\title{
Defending the Self in a Total Institution: Staff Prompting and Patient Burlesque*
}

\author{
Karen Bettez Halnon \\ Sociology, Pennsylvania State University, Abington, USA \\ Email: Kbh4@psu.edu
}

Received August 18 ${ }^{\text {th }}$, 2012; revised September 19 ${ }^{\text {th }}$, 2012; accepted September $28^{\text {th }}, 2012$

\begin{abstract}
This paper offers an analysis of forms of social interaction between direct care staff and patient members of a state institution for the "Mentally Retarded" (MR) and dually-diagnosed (MR with a mental disorder diagnosis) located in the northeastern United States. This work's significance is that it updates and extends Erving Goffman's (1961) classic study of the underlife of total institutions. It does so by delineating a sub-type of secondary adjustment to total institutions, termed ancillary adjustment. Ancillary adjustment is defined as performances of patient role that undercut the institution's official prescription for patient identity toward normalizing direct staff member identity. It is shown how ancillary adjustment arose as an unintended consequence of the institutional reforms of the 1970s, or how, under a professionally reformed and bureaucratized "New School", direct care staff members experienced themselves as disempowered and discredited as "normal" professionals and defensively and repeatedly cued hyper-stigmatized comedic spectacles through types of staff-patient interaction termed staff prompting and patient burlesque. This paper is based on a three-year fieldwork study entitled Defending the Self in an Institution for the Mentally Retarded that utilized Glaser and Strauss' (1967) and Strauss and Corbin's (1990) grounded theory methods for qualitative research.
\end{abstract}

Keywords: Stigma; Normalization; Underlife; Total Institution; GOFFMAN; Mental Patient; Mental Retardation

\section{Introduction}

"A staff member pointed to the scars remaining from a lobotomy performed on (Jason) and inquired, 'What happened?' (Jason) responded, 'They took my brains out.' The staff member probed, 'Who?' (Jason) concluded the dialogue, 'The doctors!' Laughter gushed down the hall from the dayroom" (Fieldnotes, 1992: p. 6).

"(Harry), a graying Mentally Retarded man in his fifties, was prompted again to perform a kind of sideshow when staff discussed his dramaturgical 'talent' in his presence. One staff member asked, 'Have you ever seen (Harry) when he wraps his legs around his head? It is hilarious!' (Harry) followed the indirect cue by displaying his talent, as he sat silently on the couch, staring off toward the television" (Fieldnotes, 1992: p. 14).

"Today again (Lenny) was prompted when (two male staff members) cued him to approach a 'float' (a staff member from another building covering the shift) with his usual 'humorous' approach, 'Do you like me? Do you like me? Do you like me?'

\footnotetext{
*I wish to express my heartfelt thanks to Paul Gray and David Karp for their invaluable instruction on qualitative research methods; to Kathy Charmaz and Paul Gray again for encouraging me to finally publish this work; to Vivian Qin, the editorial staff and the reviewers at Sociology Mind for their constructive comments; and especially to all those persons and/or individuals at Glendale who opened and entrusted their institutional world to me.

${ }^{1}$ The term "patient" is used in all subsequent writing (both text and quoted fieldnotes) to maximize clarity and consistency. However, several terms were used to refer to patients during the study, each successive change in nomenclature attempting to relinquish the negative connotations that caught up with the last term employed. Currently, patients/clients/residents/citizens of the institution are called "persons."
}

As he did so, drool spilled from his mouth and the targeted staff quickly moved back in repulsion. Everyone in the room burst into laughter" (Fieldnotes, 1992: p. 26).

This paper is about forms of interaction observed at a state institution located in the northeastern United States: staff prompting and patient burlesque, or direct care staff cueing patients to perform as hyper-stigmatized comedic spectacles. ${ }^{1}$ In these carefully guarded theatrical displays adult male patients were repeatedly prompted by male, working class, direct care staff members to perform beyond their already stigmatized status as institutionalized, Mentally Retarded, and/or mentally ill persons.

Patient burlesque played upon a number of symbolic displays of debasement: patient ignorance, begging, self-denigration, sexual exposure, gibberish speech, and alterations of the normative mode of communication. It also involved "comedic" scenes of patients asserting their discredited selves, violating the social space of others, and performing various animated spectacles and sideshows. It is argued that staff prompters engaged in these interactions as a method of defending their stigmatized selves through the dramatization of high contrast deviant others in a reformed and professionalized total institution dedicated to normalizing patients.

Several factors explain staff prompter stigma: lack of self-identification as normal professional employees; daily intimate contact with patients; patient elites assuming staff member roles and unofficial evaluators of employee worth; open patient knowledge disputes with higher ranked employees; a policy of normalization that bitterly coexisted alongside multiple impediments to achieving normal employee status; and on 
the face of it, engaging in what professional staff members would surely define as patient abuse. However, a sociological analysis of the multi-layered meanings of staff prompting and patient burlesque will reveal a complexity of complicity whereas the institutional arrangements share at least equal responsibility for the interactions discussed.

\section{Literature Review and Study Significance}

What is close conceptually to patient burlesque are images of Otherness produced through practices such as freak shows, blackface, pornography, and through a more particular historical case, French neurologist Jean-Martin Charcot's hysteria shows. In each of these examples, like patient burlesque, stigmatized individuals perform as super-stigmatized before an audience and, in entertaining others, magnify their already stigmatized statuses. As Bogdan (1988) puts it, in the freak show of Barnum and Bailey the extremely tall man is transformed into a "giant". Similarly, in blackface, the African American in white racist society becomes the "strutting dandy" or "shuffling darky" (Gubar, 1997: p. 113). In pornography, the woman in sexist society is exaggerated in her stigmatized status as she is reduced to a naked sexual object (Dworkin, 1989). In Charcot's theater of hysteria, the medically elusive madwoman becomes the objectified spectacle of enormously detailed taxonomological classification (Micale, 1995). In these imageslike patient burlesque-Others are portrayed as willingly objectified. While mimesis-mimicry or "burlesquing the mockers through self-mockery" (Gubar, 1997) are undoubtedly dimensions of these practices (and will be noted briefly), this paper's focus is on the value of staff prompting and patient burlesque as a form direct staff member self-defense in a total institution.

The literature on domestic violence points toward a partial explanation. Dutton's (1995, p. 83) psychological profile of the batterer provides evidence of a relationship between abuse and self-defense. Because of a typical history of parental shaming, batterers suffer from "an attack on the global sense of self”. As a defensive measure, shame-prone batterers in turn shame their partners. Dutton explains further, "These men have a need to shame and humiliate another human being, to finally obliterate their own shame and humiliation" (Ibid, 35). Martin (1976: p. 68) echoes Dutton's and also Lederer's (1968) reported links between the batterer's insecurity and domestic violence when she claims that wife beaters only experience themselves as "potent with a woman defective or somehow inferior".

"If their wives do not assume that they are inferior or consider themselves equal to their husbands, apparently these men feel they have to beat them down to size. If his wife is attractive, the batterer, in order to maintain his potency (that is, his male supremacy), has to disfigure her."

Analogous to the domestic violence situation is the social situation of patients and staff prompters. A definition of the patient as normalizing (or institutionally defined with the expectation of becoming a "culturally normative" person through re-socialization) grates against the contrasting failure of staff prompters to achieve institutional status as "normal" professionals.

Defending against a kind of "relative deprivation" of normalcy potential in the total institution, staff prompters focused their various ridiculing activities on what most directly symbolized their own exclusion from institutional normalcy. Lacking the college education to qualify as professionals, direct staff prompted patients to display gross ignorance and infantilism, and through doing so, effectively "beat them down to size". The transition from presumed normal in society (or white male pre-employee) to a structural situation in a total institution that called such normalcy into question (employee status without the educational credentials subjectively necessary to perceive oneself as a professional) became an occasion for defending the self.

Kaplan's (1980) work on "deviant behavior in defense of self” demonstrates more generally that the "self-esteem motive" lies behind a range of deviant behaviors, such as suicide, delinquency, drug abuse, and violence. Kaplan (Ibid., 9) argues that deviant behavior is likely to ensue when three conditions are met:

“1) Self-perceptions of failure to possess personally valued attributes or to perform personally valued behaviors (and selfperception of possessing attributes or the performance of disvalued behaviors).

2) Self-perception of failure to be the object of positive attitudes by personally valued others (and self-perceptions of being the object of negative attitudes by personally valued others).

3) The failure to possess and employ normatively defined self-protective response patterns that might preclude the occurrence or mitigate the self-devaluing effects of such experiences."

Kaplan notes, moreover, that "The probability of outcomes, in turn, is influenced by such variables as placement in the social structure (which influences such outcomes as disjunctions between socially defined goals and access to the goals and/or the probability of other stigmatizing experiences)."

In this paper I will explain that although staff prompters outwardly rejected the value of professional status and associated professional behaviors, they clearly experienced their status as high school graduates and their daily practical management of patients as devalued by college-educated staff who had the institutional authority to enforce their professional perspective. And unlike professional staff who were able to guard themselves from "courtesy stigma” (Goffman, 1963) through infrequent contact with patients, the job requirements of direct care staff placed their distance from patients at a minimum. Their status as normals in an institution dedicated to normalizing patients was further impeded by professional staff who permitted patients to judge staff members, by patients who assumed (at the ironic bequest of staff prompters) staff member roles, and by patient elites who actively distanced themselves from staff prompters. I will argue that the "deviant self-protective response pattern" of staff prompters was to hyper-stigmatize patients through theatrical displays and while doing so, as a kind of “jocular aggression” (Pogrebin \& Poole, 1988), mock the patient's normalization program.

The ethnographic work that comes closest to this study is Wiley's (1988) on a holistic therapeutic community for schizophrenics in which the hierarchical distinctions between staff and patients were nearly nonexistent, and where "each status converged to the extent that it was often difficult for anyone at a given time to know who was who" (Ibid., 5). At Quaesta, that sponsored a "democracy of interaction," "the attempt to exert authority by virtue of professional status (was) both formally and informally, frowned upon and negatively sanctioned" (Ibid., 9). While Wiley (Ibid., 18, 22) notes the positive consequences of "role blurring" ("an unusual sense of camaraderie among 
staff and resident"), her analysis focuses on how staff aimed to reassert their authority over patients through "subtle interactional devices." For example, when a "resident became too insistent on the democratic principle of order" in a heated debate "the staff often called attention to the individual's therapeutic 'issues'” (Ibid., 23). "Psychic trashing," a similar control technique, was used by therapists who were in "the most powerful position to define the reality of the situation over the competing definition of the resident" (Ibid., 24). Wiley concludes by outlining the "essential conditions (circumstances or characteristics) under which 'role blurring' is most likely to occur." In order of salience, she specifies "an equalitarian ideology that demystifies the role of traditional authority" and "a general deprofessionalization of the occupational or organizational context” (Ibid., 33). In this paper I will show, however, that in the case of a total institution with a clear hierarchy of staff authority, professionalization coupled with normalization (the two measures of staff and patient normality in reformed total institutions respectively) may give rise to substantial role blurring between direct care staff and patients. I will show further how, in consequence, such blurring may lead to "blatant interactional devices” for reasserting social control.

This paper contributes more generally to the literature on normalization principles (Wolfensberger, 1972, 1980; Whitman, 1995; et al.) by explaining the difficulties of implementation in a reformed total institution. The contribution lies in the lack of literature devoted to explaining such difficulties within total institutions during their last phases of operation, since (institutional pseudonym) Glendale's explicit mission, as the general undertaking of all similar institutions guided by normalization principles, is community integration of patients and eventual institutional closure. Given this charge, the relevant sociological literature focuses almost entirely on de-institutionalization, critically assessing its failures (Dear \& Wolch, 1987; Grob, 1995; Isaac, 1990; Johnson, 1990; Kip, 2000; Mechanic, 1990; Scull, 1989; et al.) and seldom highlighting its successes. The works of Bilken (1989) and Taylor, Bogdan, Biklen, and Ferguson (1989) that examine the "bright side" of community integration (Taylor et al., 1989) stand as clear exceptions. Positive assessments are typically found in professional (e.g., Malik \& Shaver, 1979) rather than strictly academic or sociological reports. While the literature reviewed focuses on assessing how well community care has been realized under the auspices of normalization principles and it counterpart, de-institutionalization policy, this paper focuses on the implications of coupling professionalization and normalization in the continued operations of a reformed total institution. More specifically, I will show how this coupling had the unintended consequence of providing an organizational structure ripe for exploitative interactional forms that would magnify rather than reduce patient deviance; and thus, undermine the central purpose of the reformed institution, to culturally prepare patients for discharge and community integration. Thus, while I do not entirely depart from typical negative sociological assessments, I will provide a closer lens on institutional analysis that appears to have been largely abandoned after the 1970s implementation of de-institutionalization policy.

The analysis to follow focuses around Erving Goffman's concept of "adjustment," as explained in the series of essays that constitute Asylums: Essays on the Social Situation of Mental Patient and Other Inmates (Goffman, 1961). In "The Underlife of a Public Institution: A Study of Ways of Making Out in a Mental Hospital” Goffman defines two types of adjustment, primary and secondary. Primary adjustment is the inmate's outward and apparent acceptance of his role and his self as patient as defined by the total institution. Of the primarily adjusted patient he says, "he is transformed into a co-operator; he becomes the 'normal', 'programmed', or built-in member" (Ibid., 189). In "The Moral Career of the Mental Patient" and in "The Characteristics of Total Institutions" Goffman describes a panoply of mortifying practices necessary for these self and role adjustments including, for example, will-breaking ceremonies, deprivation of personal property, personal disclosure through case record and staff gossip, surveillance, echelon staff authority, and regimentation of daily life. Primary adjustment is made possible by stripping the patient of his previous role and self and replacing them with the behavioral and identity expectations of the institution. Goffman says, moreover, that primary adjustment is no less than the radical transformation of subjectivity and the alternation of social worlds.

"Through this orientation and engagement of attention and effort, he visibly establishes his attitude to the establishment and to its implied conceptions of himself. To engage in a particular activity in the prescribed spirit is to accept being a particular kind of person who dwells in a particular kind of world" (Ibid., 186).

Emphasizing the resilience and expedience of human beings to defend their selves in the most constraining circumstances, Goffman shows how the patient's primary adjustment may be more apparent than absolute. Patients, he says, employ an array of strategies to defend their selves in total institutions; for example, through make-do's; working the system; avoiding hospital surveillance; designating free spaces, group territories, and personal spaces; creating fixed and portable stashes; utilizing undercover systems of communication; and engaging in private coercion, economic exchange, and social exchange. These secondary adjustments, or what Goffman collectively terms the patient underlife of the institution, "represent the ways in which the individual stands apart from the role and the self that were taken for granted for him by the institution" (Ibid., 187). Goffman succinctly distinguishes the two forms of adjustment: "To prescribe activity is to prescribe a world; to dodge a prescription can be to dodge an identity" (Ibid., 189).

Writing in 1961, Goffman (Ibid., 205) said that "secondary adjustments on the part of Central Hospital employees should be considered minor. I will therefore not consider many of the standard secondary adjustments practiced by subordinates in work organizations, such as restriction of output, 'make work', 'government work', collusive control of productivity reporting...” That Goffman's work focuses on the underlife of patients rather than staff is justified by the extensive literature he cites that accounts for the latter at the time. However, what Goffman's qualifying and typically exhaustive comments point to is the absence at the time within Central Hospital, or elsewhere reported to his knowledge, of a form of staff secondary adjustment as a double defense reaction; first, against the patient's primary adjustment as normalizing; and second, against multiple impediments to achieving primary adjustment as normal professional employee. That I am able to elaborate on this process, as "ancillary adjustment," is surely due to a shift in perspective, from Goffman's on inmates prior to reform policy, to a focus on the social situation of staff and patients after the implementation of patient normalization principles. Because this work is based upon a single institution and a subversive 
practice within it, its generalizability depends upon subsequent findings. Nevertheless, that weakness of this ethnographic work may be compensated for by the details I provide of the underlife of an institution ordinarily closed off from the public and sociological eyes.

\section{Research Methods and Study Background}

For a period of three years (1990 to 1993) I conducted a fieldwork study at a state institution located in the northeastern United States, identified throughout by the pseudonym Glendale. "Grounded theory" methods (Glaser \& Strauss, 1967; Strauss \& Corbin, 1990), and Lofland and Lofland's (1984) qualitative methods for analyzing social settings guided this research. The research focused on the general question: how do members of a total institution defend their selves? Erving Goffman's works on the presentation of the self (1959), stigma (1963) and the underlife of total institutions (1961) were used as general conceptual guides in analyzing the data. My general aim was to extend Goffman's insights on the underlife of total institutions and the experience of stigmatized persons. In accordance with inductive research methods, fieldnotes were read, coded, re-read, and re-coded until concepts and categories became evident. Once concepts and categories emerged from the data collected (and were manually placed as cut and pasted from computer documents into manila files), a more purposeful search for supporting examples and negative or disconfirming cases was pursued in the field. The broader thematic significance of the present work was given shape in the writing process. This paper represents a small slice of three years of data collected at a state-of-the-art total institution.

During two consecutive summers (1989 and 1990) I held a job as House Director, a live-in position where I coordinated weekly vacations for patient groups of ten at one of Glendale's off-grounds vacation residences. Regular Glendale staff accompanied each group of ten. Living in the same house and being actively engaged with staff and patients from approximately 5 am to $11 \mathrm{pm}$ each week provided an immersion into the lives of approximately 50 direct care staff and 120 patients each summer. Informal discussions with direct care staff during these summer months yielded a rich understanding of their perspective of working at a reformed and professionalized institution.

My job required weekly reporting of the program to the upper administration at Glendale. Over summer 1989 I cultivated a friendly rapport with them, which was enhanced by the fact that a close relative of mine was closely linked to the institutional administration. At the conclusion of the first summer program, I proposed the fieldwork study to the Glendale administration. While administrators were receptive to the idea, and told me that I would be permitted access because "we can trust you," official access to the institution involved a year-long process of seeking and obtaining formal approvals from the state department(s) overseeing the Glendale administration. By the next summer I was granted official access to facility grounds, patient records, and institutional archives. I agreed that patient and institutional identities would remain anonymous in any written documents resulting from the study. Pseudonyms for both are used throughout. Another agreement was reached concerning not describing certain unique features of the institution that would make its identity obvious to readers of published documents. I have taken all possible precautions while preserving the integrity of the data.

Weekly observation hours were spent largely talking informally with patients and staff on units, in the canteen, and elsewhere on institutional grounds. Additional formal, tape-recorded, semi-structured interviews with patients and staff members were conducted over a period of one year, but were the least informational. I found that the richest data was obtained when I held the least formal researcher role. Field notes written following each observation session, which are the basis of this paper, were the most useful source of data. Material taken directly from them is indicated throughout by use of quotations. In general, I have relied upon short quotations and summary to maximize materials incorporated in this paper. Explanatory comments are placed in parentheses within or after quotations.

Observations of patient burlesque and staff prompting between direct care staff and patients came late in the study, once staff members knew I was no longer an employee of Glendale with a reporting duty, and after many assurances that I was "not working for the administration, but just conducting an academic study." I found many staff members, who were later identified as staff prompters, highly responsive to the fact that they would have, through participation in the study, input into explaining the pejorative "book knowledge" of professionals, which they, as a whole, deemed inadequate. As one staff prompter put it, "Maybe you can tell them the way it really is. Book-knowledge, therapy, baby talking (patients) don't have anything to do with reality." Another remarked, "The psychs (psychologists) and professionals sit in the office all day. The college-educated paper pushers have no clue about what we really need." In cultivating a rapport with these men I attempted to present myself as a neutral conveyer rather than an adherent of book knowledge.

The data presented in what follows are based upon observations involving a total of 15 staff prompters and 20 patients. Patients targeted for burlesque were typically involved in more than one performance, and in a few cases, several performances. All direct care staff and patients involved in the dialogues were male. To the extent that female staff members and female patients were involved in the interactions their roles were consistently limited to audience members. As a woman researcher the gender positioning in the interactional form made it relatively easy for me to adopt an observer role.

Patient performers were primarily those who gave off clear and significant signs of mental illness, and secondarily those who gave off serious signs of moderate to severe Mental Retardation. In no case was a "high level" patient (that is, the Glendale lingo for a patient with a very low level of Mental Retardation) a participant in the dialogues. To clarify, Glendale housed a large number of residents who, while their primary diagnosis had to be Mental Retardation in order to live there, their expressions given off to me, to staff, and to patients were often much more descriptively those of mental illness than of Mental Retardation. Population mixing was the subject of much heated discussion at Glendale. The general consensus expressed by staff prompters, high level patients, and many professional staff members was that mentally ill residents were inappropriate members of the Glendale community, or physical and social threats to the Mentally Retarded. As one high level patient emphatically and loudly defended from the front of canteen one day (a place ordinarily visited only in passing by high level patients), "They think I'm mental, but I'm not! I might be re- 
tarded, but I'm not mentally ill!” As a rule, high level patients, some of whom were members of patient rights committees, who observed staff prompting and patient burlesque, ignored the behavior and to my knowledge never filed any reports. While the aim of this paper is to demonstrate how some direct care staff benefited from the construction of mentally ill and low level patients as hyper-stigmatized, it may be noted that the reticence of high level patients who observed staff prompting and patient burlesque is suggestive of their own profit from displays of radical Otherness.

As a young researcher I struggled with the ethical issues arising from the interactions I witnessed as audience member in the course of my fieldwork and reported in this paper. Conflicting allegiances to patients, Glendale administrators, and staff prompters also; as well as feeling guilty about my role as passive yet present audience member, explains in large part why this research did not find its final form as my dissertation. I present a portion of this research now as a somewhat delayed but hopefully constructive informational piece. That this paper focuses on the perspective of staff members rather than patients is not an apology for that perspective, but to provide what I believe is necessary knowledge in the formulation of efficacious solutions.

\section{Staff Prompters and Stigma}

The typical staff prompter at Glendale was a young (early 20 s to early 30s), white, unmarried, working class man whose education consisted of four years of high school. In a few cases (2 of 15), he had taken a course or two at a local community college. Staff prompters seldom traveled far beyond their community, except in the case of military training. Prompters self-reported spending their free time engaged in a variety of local town activities characteristically including playing or watching sports; drinking alcohol at parties or bars; talking about or spending time with "girls"; driving or working on their cars; or just "hanging out" with friends.

The socioeconomic position of staff prompters was a precarious one. Staff prompter high school graduates came to Glendale with the opportunity to earn a relatively good wage by community standards. In addition, they would receive liberal state benefits, and be hired as direct care "professionals". However, in their employment at Glendale these men found that they did not gain the anticipated rewards of occupational prestige, but rather, were socially located at the margins of the institution. They found their roles as professionals at Glendale discredited in a number of significant ways.

It is important to clarify Erving Goffman's meaning of stigma. Stigma is a relational phenomenon. Stigma, or spoiled or discredited identity, does not simply inhere in an attribute of a person. It is rather a case of a discrepancy between expectations and a realization, or to be "incongruous with our stereotype of what a given type of individual should be" (Goffman, 1963: p. 3). More precisely, Goffman says that it is a discrepancy between virtual identity and actual identity. Stigma is falling short of virtual identity, or "an undesired differentness from what we had anticipated" (Ibid., 5). To be normal, on the other hand, is to be congruent with such demands and expectations, or to be one who displays a match between virtual and actual identity. Upon hiring, the virtual identity of staff prompters at Glendale was that they were professionals. Discrepant with that expectation, the actual identity of staff prompters was that they did not perceive themselves, nor did others perceive them as professionals. For a large variety of reasons explained below, they were excluded from the category of normal employees at Glendale.

Lack of Self-Identification as Professional Employees. The single, expected and demanded role of staff members at Glendale was to act as a professional. Regardless of educational background, all new employees were inducted as professionals through a full time, one-week orientation program in which empathy for patients and respect for patient rights were central themes. A major impediment to achieving normal institutional status was therefore not lacking knowledge of the requirements of professional comportment, but a discrepant definition of the role. Professional was a term used pejoratively among staff prompters to refer to higher-ranked, college-educated employees at Glendale who did not engage directly and continuously in the day-to-day care of patients. Professional, for staff prompters, was a negative term that referred to upper administration, psychologists, social workers, nurses, and some aloof or educated building managers. College-educated professionals, according to staff prompters, were "paper pushers," "educated people who don't know shit about (patients)," employees who "spend all day in the office and come up with behavior plans that have absolutely nothing to do with what (patients) really need. But we have to implement them!” Thus, the role of professional was foreign in terms of self-identification. In absence of that selfidentification, the achievement of normal status at Glendale was, to begin with, a highly dicey prospect.

Engaging in "Patient Abuse". Glendale's official understanding of the institutionalized patient in need of services was as a social deviant. But patient deviance was understood to be largely correctable through the use of normalization devices such as behavior plans, individual psychotherapy, employment programs, hobby groups, 12-step programs, and circle groups for the development of interpersonal skills. What aspects of deviance were not rectifiable through such measures were to be compassionately accepted. Thus, Glendale's mission was to reduce patient deviance, not to expand it.

To entice patients to perform beyond the official self and role prescribed by the total institution, or beyond the patient's primary adjustment, was a serious transgression. Such interactions would be considered, if detected, egregious and reprehensible not only because they violated patients' legally enforceable rights, but also because they constituted a subversion of the institutional goal of normalizing patients. Therefore, to prompt patients to act like hyper-stigmatized spectacles was to abandon the expected role of any employee of the institution, and to be subject, if caught, to termination and legal prosecution. Patient abuse, in the form of actively ab-normalizing patients, was thus grossly discrepant with the expected role of Glendale, and thus fully discredited staff prompters from the status of employee normals. However, that staff prompters guaranteed their selves as discredited through a set of interactions with patients that would be condemned by professionals was more an instance of secondary deviation than of primary deviation (Lemert, 1951). Below I will explain how patient burlesque and staff prompting did not constitute but rather compounded a complex institutional situation that impeded staff prompters' expected normal status or primary adjustment as professional employees.

Daily Intimate Contact with Patients. The normal status of staff prompters as professionals was further hampered by their daily situational closeness to mentally ill and Mentally Re- 
tarded patients, which threatened with "pollution" and "contamination” of stigma (Goffman, 1963; Goffman, 1961). Moreover, the threat of "courtesy stigma” (Goffman 1963), or "catching" stigma through association, was not possibly resolved through the general strategy of "mystification" or social distance (Goffman, 1959). This is because of the specific nature of staff prompters' daily work, which required ongoing verbal interchange with patients and intimacies such as seeing, washing, and touching patient body parts and excretions. A high level of intimacy placed staff prompters' social distance at a minimum. It was this comparative difference that made it comparatively difficult for direct care staff to maintain the reality of themselves as professional normals. Stability of self as a normal employee was a more realistic possibility for psychologists, social workers, and administrators, and the like, who were shielded from courtesy stigma through much less frequent and intense interaction with patients. The "paper pushers", largely because of the bureaucratic necessities of extensive behavioral and therapeutic planning and documentation, did indeed spend the majority of their time in their offices or removed from the regular round of life on the wards. This may explain why when they did appear they often made dramatic displays of their (ostensible) knowledge of patients.

Open Knowledge of Patient Disputes with Higher Ranked Professionals. Staff prompter stigma through close association with patients was compounded by de facto professional exclusion through open disputes with higher ranked professionals concerning patient care. Arguments were typically over what "really" constituted normalization. Disputes centered on issues such as how patients should dress. Should Jerry be allowed to wear a Mickey Mouse shirt and should Shawn be allowed to dress up like a firefighter? The most contentious issue concerned paperwork taking precedence over time that might be spent engaged in more normalizing activities with patients. A male patient who was seeking a sex change was also a heatedly discussed topic among staff prompters who interpreted the patient as homosexual, who agreed that that "being a fag is not normal," and who expressed incredulity over the rumor that the operation might be funded by the State.

Professional explanations of patient rights to dress as patients choose, guarantees of compliance with state and federal guidelines for care and service through documentation, and staff prompters perception of professional assistance in a patient's sex change (that was in fact quietly and unofficially discouraged by professional staff),were viewed antagonistically by

\footnotetext{
${ }^{2}$ The insistence of more realistic normalization principles was inconsistent among staff prompters. Beyond the patient burlesque and staff prompting interactions delineated in this paper, "kitchen switching" stood as a major contradiction. Staff prompters expressed much hostility over the fact that "patient snobs" (elite patients to be discussed below) were regularly allowed in the kitchen by "professional" staff. According to staff prompters, the "kitchen area is for staff, not (patients)." It was of considerable consternation that patient snobs were ordinarily allowed to occupy the kitchen with many "professional staff," sharing a cup of coffee, cigarette, or extended conversation. During my first summer at the Glendale vacation residence I was accused when doing the same, or of not treating them like (patients)." When mixed interactions between professionals and elite patients took place in the kitchen, staff prompters avoided the area, coming in briefly only to do what was necessary. However, when professionals were absent, staff prompters rigorously enforced "low level" patient exclusion from the kitchen, but at the same time tolerated patient snobs who often (like prompters, in the first case above) expeditiously passed through. I interpreted this behavior on the part of patient snobs as a statement of their exceptional status as patients, and I interpreted the silent disapproval of this behavior on the part of staff prompters as their uneasy recognition of it.
}

many direct staff and staff prompters in particular ${ }^{2}$. While most of the hostility toward the requirements of implementing normalization principles was expressed beyond the earshot of higher ranked staff, sometimes direct care staff would directly dispute issues. In these cases, their extensive practical knowledge of patients was often discounted when higher ranked professionals corrected and condescended to them in the presence of staff and patients. These open disputes informed all who witnessed them of who the "real" professionals were, and in consequence, undermined direct care staff members' expected occupational status as professionals. Thus, in this case, status ambiguity as normal was not due to lack of social distance as in the case of intimate daily contact with patients. In this instance, knowledge contests between direct care staff and higher-ranked professionals created a large space of role distance between employees at Glendale.

The association between knowledge-of-patient disputes and inappropriate patient care may be exemplified by explaining a common New School (Glendale lingo for after-reform) activity of professional staff, which staff prompters sardonically termed "baby talking the (patients).” During a full day of observation one patient continually harassed a staff prompter by following him from room to room, physically blocking him, talking directly into his face, and repeatedly demanding "Take me out for spaghetti and meatballs!" From fieldnotes, the event is recorded at greater length.

"(Zachary) must have made this demand a hundred times during the day! Finally, at his breaking point, (the staff prompter) reprimanded him in a loud voice, 'Shut up, already! I've had enough of you!' As he did, a psych emerged from the office into the hallway, having overheard the interaction. In the presence of (the patient), (she) condescended to the staff member, told him that his response to (the patient) was 'not appropriate,' and proceeded to model a gentler, ostensibly more therapeutic interaction, that is, to baby talk the (patient). The disgruntled staff member listened quietly and nodded his head. After the psych departed, (the staff member) declared to a sympathetic co-worker that his response was hardly excessive by normal standards. 'A punch in the face would be his normalization in the real world!' (the staff prompter) declared. A short time later I could hear a physical altercation inside (Zachary's) room. It sounded as if (the staff member) threw him up against the wall while he was yelling at him. (The staff prompter) emerged from his unofficial office, (Zachary's) room, and announced victoriously, 'Now, I'm in charge!'” (Fieldnotes, 1992: p. 34).

Without exception, in informal interviews staff prompters self-described themselves as disrespected and unappreciated by professionals and expressed antagonism toward them. Moreover, while staff prompters expressed disbelief in the more credible knowledge of patients and their treatment by professionals, they expressed a discontented yet outwardly deferential understanding that such knowledge was the more institutionally legitimated knowledge. The observed disposition of staff prompters was quintessentially authoritarian (Adorno et al., 1950).

Patients Assuming the Roles of Staff Members and Evaluators of Staff Prompters' Professional Worth. The assault on staff prompter normal self was reinforced by the roles assumed by a small group of high status mildly Mentally Retarded patients. "(Patient) snobs," as they were labeled by staff at Glendale because of their selectivity in interactions with both staff 
and patients, overtly distanced themselves from staff prompters. Eye contact was avoided. Entrance to rooms occupied by staff prompters was delayed. Conversation was avoided or sharply curtailed. Casual conversation between the parties was never witnessed. Tension marked all minimal interactions. Patient snobs' expressed attitude toward prompters was one of civil but evident disdain. When prompters verbally addressed patient snobs, they listened politely and complied to the extent the request was deemed reasonable; if not, the typical response was to inform the prompter of the "correct" institutional policy and to walk away, much like professionals condescended to staff prompters.

It is important to emphasize that as a rule patient snobs limited their interactions to those with professional staff, a small exclusive group of especially high level patients, and a few elderly patients for whom they assumed caretaker roles; for example, for a deaf-mute patient they always addressed with "hey, dummy." The exclusiveness of patient snob interactions with others magnified the stigma of staff prompters at Glendale because what was common, indeed, about patient snob selectivity was their equally emphatic exclusion of "crazies" (patient snobs' label for seriously mentally ill patients) and staff prompters. This judgment effectively placed the two groups in the same general category of seriously stigmatized others ${ }^{3}$.

To intensify the already tense relationship between snobs and prompters, a commonly utilized informal measure of a "good" staff member by many professional staff at Glendale was the patient snobs' opinion of the staff member. This opinion favored considerably in me gaining access to the institution. Two professional staff who were closely affiliated with patient snobs informed me that Hal, the leader of the patient snobs, "took it upon himself to put in a good word for me" with the administration. At Glendale, such reports were given serious consideration in accordance with patient rights protections, especially in the case of patients with a minimal level of Retardation who could express their opinions with greatest coherence. Thus, patient snobs were equipped with the power to define the general worth of staff, which is to say inevitably and understandably to define staff prompters as unprofessional. Such authoritative knowledge of staff by patients bitterly coexisted alongside the frequent dismissal of staff prompters' knowledge of patients by professionals. Therefore, a further source of stigma for staff prompters was that patient snobs reversed the usual social distance protocol. Patient snobs deliberately and explicitly distanced themselves from staff prompters and were endowed with the authoritative knowledge to judge them. In other words, the stigmatized patient assumed the role of the avoiding, judging normal. Why patient snobs did not manage to have staff prompters fired was assuredly due to the social benefit they gained through patient burlesque. Much like what prompters gained through the displays of hyper-stigmatized mentally ill patients, high level patients gained perhaps several-fold considering their even closer social proximity to them as institutionalized "patients".

A more explicit yet equally anomalous alliance between staff

\footnotetext{
${ }^{3}$ A notable exception to patient snobs' explicit avoidance of patient "crazies" was the event of a funeral. For example, when a patient in the latter group died, each of the patient snobs attended the funeral, shook the hands of the deceased friends standing in the reception line, and expressed a few apparently sincere words of condolence. This exceptional behavior on the part of patient snobs was a central staple of the next week's staff conversation.
}

prompters and patient snobs explains an additional source of stigma for staff prompters. Elucidating it requires a brief history of institutional arrangements between patients and staff members. In the Old School (the institutional lingo for Glendale before institutional reforms and professional restructuring) patient care was charged to a small group of laterally organized staff, under the supervision of a superintendent and very small support staff. Maintaining order in the Old School was fairly simple, as one staff member recalled, "if the kids (that is, adult patients) acted up, you took them out behind the building. That usually solved the problem." A common subsidiary strategy of governing mass patients for Old School staff was the designation of "patient heavies" (my descriptive term, not Glendale lingo) who served as staff assistants in gaining the compliance of uncooperative patients through verbal intimidation and corporal punishment. A small number of "hard working, more intelligent kids (adult patients)" were selected to "keep the others in line," reported one Old School employee. It was also often the case that a staff member who struggled with the assignment of managing two buildings at a time would delegate supervisory authority of one of the buildings to a patient heavy.

Three patient heavies, at the time of this study in their late sixties and early seventies, still retained authority that was delegated years before. Significantly, these men were also the most prominent patient snobs. Staff prompters, aware of the legendary roles of patient heavies, occasionally settled "behavior problems” by threatening to get Hal, Joe, or Jim. “Acting out" patients responded to the simple threat to make a telephone call to a patient heavy. It should be noted that while patient heavies/patient snobs, as a rule, did not interact with staff prompters as an expression of their disrespect for them, they did as a rule accommodate requests to assume their Old School role. This role ordinarily involved simply walking into a room and asking in a commanding voice, "What's going on here?" or "What's the problem?” A patient heavy's authority no longer rested on his physical ability to impose physical harm, as the age, health, and general physical condition would have made the successful application of corporal punishment on younger patients highly improbable. Rather, patient heavies' authority rested on their legendary reputation.

It appears that even while generally estranged from each other, staff prompters and patient heavies each benefited from this particular temporary alliance. By assuming a position of authority directly over patient "crazies," patient heavies reclaimed and re-lived their near-staff status of the Old School; a method of nearly escaping their demoted and less differentiated status as patients in the New School. And of at least equal significance, they also displayed a managerial efficiency exceeding that of staff prompters, the official staff members of the New School. While prompters may have benefited from the immediate resolution of patient behavior problems, and may have even given others the temporary impression that they could direct the actions of the least socially accessible patients, they did so by appealing to their more effective behavior management skills. Despite the rewards, the result was a further blurring of the lines between themselves and patients.

The Policy of Normalization. The 1970s was an era of reform for institutions for the Mentally Retarded in the United States. A hierarchy of college-educated administrators, psychologists, social workers, nurses, and building managers trained in the vocabulary of normalization assumed positions of authority and prestige in the institutions. One of the leading experts on the 
subject, Wolf Wolfensberger (1980), defined the concept of normalization as "the utilization of means which are culturally normative as possible, in order to establish and/or maintain personal behaviors and characteristics which are as culturally normative as possible." Glendale's organizational guidelines for the care of the Mentally Retarded defined normalization in nearly identical words.

The policy of normalization presented a problem for staff prompters. The subjective perspective of staff prompters was that they experienced themselves as abnormalized within an all-encompassing total institution dedicated, at the same time, to normalizing patients. As one staff prompter expressed the typical jealous sentiment, "All we ever hear about is (patient) rights this, and (patient) rights that! What about our rights? We don't have any rights." The perspective of prompters was that while they were constantly disrespected and devalued as and by professionals, patients were explicitly invited to normal status through a program entrenched with a philosophy of patient rights. Seen in this light, the professionally-directed normalization of patients was not merely perceived as a poorly informed behavior management strategy, as staff prompters often complained; but more "dangerously" and less discursively, a policy that reversed the "proper" staff and patient roles as normal and stigmatized respectively, or what translated equivalently as a "faulty" over-emphasis on patient rights. To invert this reversal staff prompters found a dramaturgical solution.

\section{Staff Prompting and Patient Burlesque}

The staff prompter cued a patient with a short, familiar phrase. The patient responded in a rehearsed manner. The audience laughed at the vivid display of hyper-stigma. The burlesque was repeated on numerous subsequent occasions on cue, before a carefully segregated audience. Most patient burlesques originated from incidental and potentially transitory odd displays by a patient in the presence of a staff prompter. In many cases, however, original performances were authored entirely or heavily edited by them.

Patient burlesque was prompted through a variety of methods: by specific verbal or gestural initiating cues; by staff prompters talking enthusiastically about a performance in the presence of the patient performer; by staff prompter impersonations of the performance the company of a patient performer; by staff prompters providing the necessary lines of dialogue on cue (in the cases that the staff prompter's lines were intermediary links in a patient-initiated performance); and by staff prompters bluntly asking the patient to perform. In no case did I witness a staff prompter negatively sanction a patient for refusing to perform. In a few cases, repeated prompts were given to elicit compliance. The usual scenario was that the patient willingly participated, presumably for the attention he received. However, this may have been the paradoxical result of stigmatized patients resolving issues of "attention deprivation" (Derber \& Magrass, 1988), which is therefore to trade in one assault on the self ("social invisibility") for another ("objectified spectacle”).

It is important to stress that staff prompters prompted patient burlesque over and over and over again. The effect of the repeated performances was that potentially transitory deviant behaviors of patients became fixed deviance characteristics of them. In more precise sociological nomenclature, staff prompting and patient burlesque had the effect of transforming "residual rule-breaking” into "careers of deviance” (Scheff, 1984;
Becker, 1963). The analysis to follow then addresses Thomas Scheff's (1984: p. 48) question,

"If residual rule-breaking is highly prevalent and is usually transitory, ... what accounts for the small percentage of residual rule-breakers who go on to deviant careers? To put the question another way, under what conditions is residual rulebreaking stabilized?”

In the pages to follow I will illustrate how the labeling process Scheff writes about at length can be facilitated through a type of highly theatrical acceptance of the deviant role.

While patient burlesque took place in the covert "backstage" (Goffman, 1959) activities of staff prompters, patients some times initiated performances in the presence of staff who were not directly involved in the backstage activity. These "frontstage” (Ibid.) performances took place when a prompt was initiated by the lines of a patient and required minimal or no lines of staff members. In these cases, non-confederate staff appeared to consider the burlesque activity merely idiosyncratic of the patients involved. And when patients performed for these "mixed audiences" (Ibid.), staff prompters often took on a disquieting silence. They were assuredly crossing their fingers that the dangerously close back and front stages would stay intact.

While patient burlesque was ordinarily performed for an exclusive clique of seasoned staff prompters, others who were judged allegiant to unofficial employee practices, or at least indifferent to the enforcement of official rules and regulations governing patient care, were occasionally permitted into the backstage. However, backstage activity was carefully guarded from the out-group composed of administrators, psychologists, and other staff members who were perceived to advocate and enforce the official policies of the institution which placed significant emphasis on patient rights; that is, the professional staff. I often wondered, with substantial discomfort, why I was let in. I finally concluded that it was a combination of trust that was cultivated, my own working class background which I purposefully made known to staff prompters, and the view of staff prompters that there was nothing really wrong with the activity, even if professionals would assuredly view it that way.

Below I provide a thematic analysis of the content of staff prompting and patient burlesque. The central theme is the humor of the patient's hyper-stigma. The point of the performances was to vividly display the patient's debased and disenfranchised condition. A prominent secondary theme woven within the central theme is the value and power of phallocentric heterosexuality. The content of the latter type of prompted burlesque is sexist, homophobic, and some times violent.

\section{The Humor of Hyper-Stigma}

Hyper-stigma is displayed in nine humor themes in the content of staff prompting and patient burlesque. The overall effect of these interactions was the extreme debasement or mortification of the patient. This was achieved through magnifying the patient's limited intellectual ability; directing the patient to self-denigrate himself before an audience; transforming sexual violence against the patient into a form of entertainment; invading the patient's sexual privacy; eliciting humor from the self-assertion of a discredited person-patient; laughing at the patient as he spoke gibberish or dramatically sang his activities and complaints; and through deriving humor from patient begging, patient violations of social distance, and patient performances of degrading sideshows. 
The most general humor theme in the data analyzed was the patient's limited intellectual ability. Prompted burlesques on this theme provided blatant displays of patients' disqualification as intellectually competent adults. Many examples are illustrative and can be divided into patient-initiated and staff-initiated dialogues. Exemplifying the former type, Robert started a dialogue by asking, "Can I ask you a question?" The staff prompter joined in by answering, "Yes, Robert.” Robert demanded, "I want a Fresca and I want it now!" (or "Give me a new suit today!” or "Give me a cigarette!”) The audience laughed with delight. The humor of this prompt was drawn from Robert characteristically making a demand following the request to ask a question; or more precisely, the humor was Robert's apparent ignorance of the difference between a question and a demand. A second example of patient-initiated burlesque involved Carl looking down, patting his bulging stomach, and saying in a slow, long, throaty voice, "Hi, Buba!" The humor of this prompt was the reduction of a macho (suggestively, beer-drinking) man, to the resemblance of child amusingly attributing impossible autonomous animation to bodily organs, much like a two year old child imaginatively applies animation to all sorts of inanimate things. A final example of a patient-initiated burlesque involved Mark approaching staff members and asking, "Is it snowing out?" The humor of this burlesque was drawn from the fact that Mark was apparently unaware of seasonal changes, as he asked this question during the entire year.

The humor theme of the patient's limited intellectual ability was also contained in a number of staff-initiated prompts. A flagrant example that drew humor from the limited intellectual ability of patients occurred whenever a staff prompter pointed to the scars remaining from a lobotomy performed on Jason and inquired, "What happened?" Jason responded on cue, "They took my brains out.” The staff prompter probed, "Who?” Jason concluded the dialogue, "The doctors." Laughter gushed down the hall from the dayroom the day I was first introduced, through this example, to the practice of staff prompting and patient burlesque. Thereafter witnessed dozens of times, the dialogue was always the same. When in-group staff members wanted to present this highly "entertaining” exhibition to ostensibly safe uninitiated others they instructed them to present Jason with the appropriate cues. The apparent humor was that Jason was ignorant enough to partake in this extremely self-mortifying dialogue, providing his audience with a humorous testament of his "lack of brains" for doing so.

A milder example of staff-initiated burlesque was when Eddie was presented with any question that required a numerical answer and he routinely answered "ten." The obvious cue was any question requiring a numerical answer. A similar burlesque took place when a staff prompter pointed to any animal except a duck and would ask Richard, "What's that?” Richard exclaimed in a child-like voice and manner, "A duck!" The humor was that again, like a very small child, Richard was seemingly incapable of making distinctions between types of animals.

A second humor theme in patient burlesque was the patient's self-denigration. This theme can be exemplified through a fill-in-the blank prompt. A swear was rhymed with the patient's last name, whereby the patient was instructed, in effect, to degrade himself by the action of the prompting activity as well as by the content of the interchange. The staff prompter would say slowly with a long anticipatory breath, "(John Schick)...” And
John would answer as accustomed, “... is a (prick).” Staff prompters would snort with delight as John looked toward them, smiling softly, as he compliantly and effectively closed the gap between self-reference and identity (Strauss, 1972: p. 380).

A third humor theme was sexual violation. For example, one staff prompt demonstrated a clear and disturbing disregard for the suspected sexual violations committed against a patient. As the background story was told, the patient prompted in this burlesque was suspected to be raped by his father when away on home visits. In the prompt referencing the information the staff prompter inquired, "(Jake), what happens when you go home?” Jake replied as expected, "My father fucks me up the ass.” Loud throaty laughter would follow. Sexual violation in another context involved the invasion of the patient's sexual privacy. For instance, a patient known to masturbate was recurrently prompted when staff prompters entered his room and asked, “What are you doing?” Joe would respond as rehearsed, "I'm fucking the bed."

Being diagnosed Mentally Retarded, and often mentally ill as well, and being a resident of a public institution with all that implies produces such a degree of stigma that the patient, it is frequently presumed, is less than an ordinary person (Goffman, 1961). From this perspective it could be constructed as humorous when such fundamentally discredited persons strongly assert themselves. An example of the humor of the self-assertion of a discredited person, a fourth humor theme in patient burlesque, is exemplified by the way Lenny disputed an action or instruction of a staff member. When doing so he would stare them in the eye, wave his pointer finger in their face, and threaten angrily, "I’m gonna tell my mother!” or "You're going to court!” The audience would burst into laughter. Another case in point was when Larry would make a request of a staff member. Directly following the appeal he would command loudly, "Please. And don't ever forget to say thank you!" or "Don't think about it. Just do it!” Again the staff prompters would chuckle, seemingly ignorant of the possibility that Larry may have been surreptitiously mocking their authority.

A fifth humor theme of patient burlesque is the patient speaking nonsense. For example, Vincent initiated a dialogue when asking and approaching a staff member, "What do you think? Am I right or am I wrong?” The staff prompter joined in by questioning, “About what?” Vincent completed the dialogue, “Nevermind! Just tell me. Am I right or am I wrong?” Vincent's burlesque was prompted habitually through impersonation, direct request to perform, and discussions of the humor of the dialogue in Vincent's presence. Other examples of patients speaking nonsense include Paul declaring schizophrenically to anyone present, "I am Gloria Sticks. I am everyone. Everyone is me;" when Sean announced excitedly, "Come on down. You're the next contestant on the Price is Right;” and when Lenny reverberated enigmatically, "Purple sperm. Purple sperm. Purple sperm.” Language being the fundamental building block of culture, to speak a form foreign or indecipherable to others is, in effect, to reside fundamentally outside that culture. Therefore, the humor of patients speaking nonsense for staff prompters was the humor of the patient's radical cultural departure.

A sixth humor theme of patient burlesque, with similar implications discussed above, is the humor of patients altering the normative mode of communication. Lenny exemplified this theme when he replaced ordinary speech with singing. He performed a marching song every morning after breakfast, standing up at the table and singing "Anchors Away" while he 
marched. He was also known to and encouraged to sing "Jumblelye” and “The Good Ship Lollipop.” When Lenny was angry he sang "Eight Days a Week" while taking his morning shower. This patient's vivacious performances were the most favored among staff prompters.

Lenny's performance borders on a seventh humor theme, the patient's spectacle and sideshow. This theme was illustrated when Carl said "Buckwheat!" as he took off his hat and snapped the nail of his pointer finger off his thumb, hitting his forehead. The snapping was done repeatedly and in quick motion. The humor was drawn from the reduction of a heavy-built, potentially physically dangerous, towering man to a silly slapstick ninny. Harry, a graying Mentally Retarded man in his fifties, was prompted to perform a sideshow when staff discussed his theatrical "talent" in his presence. A staff prompter would say, "Have you ever seen (Harry) when he wraps his legs around his head? It is hilarious!" Harry followed the indirect cue by displaying his talent, as he sat silently on the couch, staring off toward the television in front of him. Staff members chortled and cooed. A soft smile revealed Harry's satisfaction with the performance and belied his general "expression given" (Goffman, 1959) of his obliviousness to the staff conversation and his simply coincident display. Bernie joined the sideshow from time to time with his talent of making all sorts of realistic animal sounds: cows, ducks, cats, horses, etc. The effect of spectacle and sideshow was to provide a theatrical display, a magnification, of the perceived oddity of the patients involved.

One of the folkways of total institutions is begging. This is the consequence of many patients lacking or losing, through extortion, distraction, or theft, money necessary to acquire desired goods. Begging functioned as a corrective measure for patients reduced to a condition that precluded the immediate possession of monetarily obtained resources. As further thematic humor content, staff prompters exploited this disenfranchised condition. For example, Felix, a tall, quiet man towing a garbage bag in hand, would shuffle around Glendale grounds approaching anyone he encountered, saying softly at first and gradually speaking more quickly, loudly, and aggressively if the person approached did not comply, "Can I have a penny? Come on. Give me all your pennies!” A similar humorous begging display was cued when staff prompters shortly delayed giving Fred his hourly cigarette, and awaited the standard comedic moment when he would compliantly slur in a long deep voice, “Can I have a goooood cigarette today?” As the brawny, six and a half foot man stood before them with a passive expression in his eyes, he held out his two large, hairy fingers up in air in anticipation. The humor of patient begging — an eighth humor theme of patient burlesque-was drawn from the begging action and the diminutive level of begging.

A final patient burlesque humor theme is the patient violating social distance. Exemplifying this theme was when Lenny would often shuffle up to a staff member, puts his face in theirs, and drool about or on them while asking repeatedly, "Do you like me? Do you like me? Do you like me?” The humorous moment was when targeted staff members expressed repulsion as Lenny approached them in the manner described. This prompt was employed in a way similar to a "kiss up" prompt. In both case, the patient was used to playfully tease other staff. The kiss up prompt originated when Alex did not "behave" in the building and then wanted to go to the evening activity, Bingo. The staff prompter involved told him that if he wanted to go he would have to "kiss up" to the other male staff member present. The degree of detail of the staff prompt was not heard as the staff prompter whispered in the patient's ear while laughing with a trickster's grin and peering through the corner of his eye toward the targeted staff member. The result was that Alex walked up to the targeted staff member and attempted to kiss and hug him. The staff prompter looked on with laughter, asking the targeted staff member in a mischievous fashion if he liked it. Here we clearly see the fun made of homosexuality and the level of intellectual ability of the patient. It was constructed as "funny" that the patient qua pawn literally interpreted the instruction to kiss up and that the homophobic staff member squirmed and pushed the (feminized) patient away as he repeatedly and gently tried to kiss and hug him.

\section{Discussion}

I have argued that staff prompters experienced themselves as stigmatized in a reformed total institution because they were unable to adjust to their normal and expected roles as professionals. Sources of stigma were that staff prompters did not self-identify as professionals; worked in intimate contact with patients; were often openly corrected in their patient knowledge by higher ranking professionals; were negatively evaluated by unofficial staff-evaluator patients; and were dependent upon the greater managerial skills of patient heavies. Experiencing themselves as abnormalized in an institution that explicitly invited patients to normal status, prompters defended their selves through a subtype of secondary adjustment, or ancillary adjustment, termed staff prompting and patient burlesque.

Theatrical displays of hyper-stigmatized patients served as the unofficial staff prompter program of staff member normalization. Burlesquing the patient's grossly limited intellectual ability sharply contrasted with staff prompters' high school graduate status when the patients confused questions and demands, attributed autonomous animation to bodily organs, misunderstood numerical relationships, misidentified animals, and ignorantly announced their lack of brains. Patients were further debased through an implicit comparison via patients' linguistic incoherence as song replaced speech; when speaking schizophrenic, charismatic, or enigmatic nonsense; when demonstrating lack of self-efficacy and lack of integrity through asserting discredited selves; through performing as slap-stick ninnies; through begging for pennies and cigarettes; through drooling while asking for approval; and more generally, through participating in any staff prompting and patient burlesque interaction.

An additional benefit of patient burlesque for staff prompters was that it served as vehicle for expressing vehement phallocentric and heterosexist power. For example, it was displayed repeatedly, crassly, and violently when Jake announced that he was anally raped by his father; when John's identity was reduced to a "prick;" when Joe declared his "fucking” activity; and when Alex elicited repulsion from a presumably homosexual advance.

Phallocentric heterosexism was also expressed in burlesques that conveyed contempt for women professionals who constituted a vivid presence among the higher ranks of Glendale's hierarchy. For example, a frequently reenacted burlesque was directed at a top female administrator of Glendale and required the targeted patient to be highly animated in his theatrical display. The staff prompter asked Sam, "What does (Leslie Johnson) look like when she has an orgasm?” Sam exclaimed on cue, 
"Do the monkey!" while he wildly shook his face, with his bottom lip puckered out, his cheeks wiggling from side to side, and his eyes bulging and staring blankly ahead. Recasting women's authority in terms of animalistic sexuality was a method of psychologically diffusing that authority in the minds of staff prompters. Why this diffusion was especially important for staff prompters was because prompters lacked authority, did not think of themselves and were not thought of as professionals, and as a group were composed exclusively of men. In consequence, prompters experienced women's professional authority as a triple threat to the integrity of their professional selves.

Moreover, patients burlesquing as hyper-stigmatized, constructed as humorous, may be considered a form of "jocular aggression" that "avoids direct confrontation with a superior that could lead to organizational sanctions" (Pogrebin and Poole, 1989: p. 189). Much like what Pogrebin and Poole (Ibid., 189-191) found in the case of police officers, this kind of humor "reinforces the solidarity of individuals within the group because it is based on shared expectations. Like jokes, it causes a collectivity of laughter that strengthens the group's social cohesion.” By laughing at—and often with—stigmatized patients - staff prompters mocked the patient's program of normalization and surreptitiously promoted their own program of staff normalization. As an out-group to professionals, laughter functioned, as it often does, to strengthen group solidarity (Coser, 1959; Coser, 1960; Martineau, 1972). If not integrated as normals at Glendale, then at least staff prompters could be members of a tightly wedded group in manly camaraderie with male patient performers. Moreover, as Durkheim (1997) observed so long ago, the likelihood of counter-cultural groups increases with the complexity of the division of labor. It appears then that the well-intended professional reforms of the 1970s had the unintended consequence of cultivating an organizational environment ripe for abuse-or at least a rich organizational counter culture-by those structurally situated at the bottom. Stated from another important angle, patient residual rule breaking was transformed into careers of deviance as staff prompters defended their selves as normals in a total institution.

Finally, it must be noted that staff prompting and patient burlesque took place amid a "shaky" reality, or in an organization explicitly devoted to normalization. What made counterdefinitions of the institutionally adjusted patients stick was precisely the repetitiousness of the dialogues. Berger and Luckmann (1966: pp. 153-154) maintain, instructively, that reality is "shaky" if one does not speak of it. They say that conversation:

"gives firm contours to items previously apprehended in a fleeting and unclear manner... Generally speaking, the conversational apparatus maintains reality by 'talking through' various elements of experience and allocating them a definite place in the world... language objectifies the world... language realizes a world, in the double sense of apprehending and producing it... In conversation the objectifications of language become objects of individual consciousness... In the widest sense, all who employ the same language are reality-maintaining others... In order to maintain subjective reality effectively, the conversational apparatus must be continual and consistent."

In further backstage activities with staff prompters, sharing beer with them after work, I witnessed recurrent burlesquing of the patient burlesques. Replayed with no less animation, and in manly contests for best impersonations, these subjectively disempowered and devalued working class men defended their selves over and over and over again. Berger and Luckmann's words thus draw our attention to the power of the conversational apparatus. It was precisely the repetitive quality of staff prompting and patient burlesque interactions within and outside Glendale, or by staff cueing patient burlesque in Glendale and reenacting performances as recreational activities after workthat continually and consistently reinforced the "shaky" reality of the patient's contrasting hyper-stigma.

The findings reported here are as unsettling as the behaviors I observed in the course of my research at Glendale. This, I suppose, is the price of the "sociological imagination" (Mills, 1961). What I have attempted to do in this paper, and in the analysis of data upon which it is based, is to temporarily suspend my judgment of the ethical or moral meaning of staff prompting and patient burlesque, at least to the extent that I was able to see the motivation for it. Objectivity is never clean, but only a conscientious approximation.

\section{REFERENCES}

Adorno, T. et. al. (1950). The authoritarian personality. New York: Harper.

Berger, P., \& Thomas, L. (1966). The social construction of reality: A treatise in the sociology of knowledge. New York: Anchor Books.

Becker, H. S. (1963). Outsiders: Studies in the sociology of deviance. New York: Free Press.

Bilken, D. (1989). Purposeful Integration inherently equal. Exceptional parent, 19, 62.

Bogdan, R. (1988). Freak show: Presenting human oddities for amusement and profit. Chicago: University of Chicago Press.

Coser, R. L. (1959). Some social functions of laughter. Human Relations, 12, 171-187. doi:10.1177/001872675901200205

Coser, R. L. (1960). Laughter among colleagues. Psychiatry, 23, 81-95.

Dear, M. J., \& Wolch, J. R. (1987). Landscapes of despair: From deinstitutionalization to homelessness. Cambridge: Polity Press.

Derber, C., \& Yale, M. (1988). The pursuit of attention. In C. Clark, \& H. Robboy (Eds.), Social interaction: Readings in sociology (pp. 131-143). New York: Martin's Press.

Durkheim, E. (1997). The division of labor in society. New York: Free Press.

Dworkin, A. (1989). Pornography: Men possessing women. New York: Plume.

Glaser, B. G., \& Anselm, S. (1967). The discovery of grounded theory: Strategies for qualitative research. Chicago: Aldine de Gruyter.

Goffman, E. (1963). Stigma: Notes on the management of spoiled identity. Englewood Cliffs: Prentice Hall.

Goffman, E. (1961). Asylums: Essays on the social situation of mental patient and other inmates. New York: Anchor Books.

Goffman, E. (1959). The presentation of self in everyday life. New York: Anchor Books.

Grob, G. (1995). The paradox of deinstitutionalization. Society, 35, 5159. doi:10.1007/BF02693338

Gubar, S. (1997). Racechanges: White skin, black face in American culture. New York: Oxford University Press.

Isaac, R. J. (1990). Madness in the streets: How psychiatry and the law abandoned the mentally ill. New York: Free Press.

Johnson, \& Braden (1990). Out of bedlam: The truth about deinstitutionalization. New York: Basic Books.

Kaplan, H. B. (1980). Deviant behavior in defense of self. New York: Academic Press.

Kip, K.-S. (2000). The community care movement in mental health services: Implications for social work practice. International Social Work, 43, 33-48.

Lederer, W. (1968). The fear of women. New York: Harcourt, Brace Jovanovich.

Lemert, E. M. (1951). Primary and secondary deviation. In E. Rubington, \& M. S. Weinberg (Eds.), The study of social problems: Seven perspectives (pp. 192-195). New York: Oxford University Press. 


\section{K. B. HALNON}

Lofland, J., \& Lynn H. L. (1984). Analyzing social settings: A guide to qualitative observation and analysis. Belmont: Wadsworth.

Malik, K., \& Elaine, M. S. (1979). Jobs and self-sufficiency: Goals of the project. Technical support services to the developmentally disabled, region III, Final Report, October 1976 to September 1979. Washington DC: Rehabilitation Research and Training Center.

Martin, D. (1976). Battered wives. Volcano: Volcano Press.

Mechanic, D. (1990). Deinstitutionalization: An appraisal of reform. Annual Review of Sociology, 16, 301-327. doi:10.1146/annurev.so.16.080190.001505

Micale, M. S. (1995). Approaching hysteria: Disease and its interpretation. Princeton: Princeton University Press.

Mills, C. W. (1961). The sociological imagination. New York: Grove Press.

Martineau, W. H. (1972). A model of the social functions of humor. In J. H. Goldstein, \& P. E. McGhee (Eds.), The psychology of humor (pp. 101-125). New York: Academic Press.

Pogrebin, M. R., \& Poole, E. D. (1988). Humor in the briefing room: A study of the strategic uses of humor among police. Journal of Contemporary Ethnography, 17, 183-210. doi:10.1177/089124188017002003

Scull, A. (1989). Social order/mental disorder: Anglo-American psychiatry in historical perspective. Berkeley: University of California Press.
Scheff, T. J. (1984). Being mentally ill: A sociological theory. Chicago: Aldine de Gruyter.

Strauss, A., \& Julie, C. (1990). Basics of qualitative research: Grounded theory procedures and techniques. Newbury Park: Sage.

Strauss, A. (1972). Language and identity. In J. G. Manis, \& B. Melzer (Eds.), Symbolic interaction: Reader in social psychology (pp. 379385). Boston: Allyn and Bacon.

Taylor, S. J., Robert, B., Douglas, B., \& Dianne, F. (1989). Qualitative evaluations of exemplary programs. Journal of Rehabilitation Research \& Development, 26, 467.

Whitman, C. (1995). Heading toward normal: Deinstitutionalization for the mentally retarded client. Marriage \& Family Review, 21, 51-64. doi:10.1300/J002v21n01 04

Wiley, J. (1988). Role blurring in a holistic therapeutic community: An intermediary response to institutionalization and deinstitutionalizetion. Journal of Contemporary Ethnography, 17, 3-39. doi:10.1177/0891241688171001

Wolfensberger, W. (1972). The principle of normalization in human services. Toronto: National Institute on Mental Retardation.

Wolfensberger, W. (1980). The definition of normalization: Update, problems, disagreements and misunderstandings. In R. J. Flynn, \& K. E. Nitsch (Eds.), Normalization, integration, and community services. Baltimore, MD: University Park Press. 